\title{
The Strategy Framework of Product Life Cycle Cost Management
}

\author{
Fengzhou WANG ${ }^{1, a}$, Tengmin KE ${ }^{2, b}$ \\ 1,2School of Business Administration, Jimei University, Xiamen 361021, China \\ afzhwang@jmu.edu.cn; b1570255191@qq.com
}

Keywords: product life cycle; cost management; strategy framework

\begin{abstract}
In knowledge economy and information age, the full life cycle cost management mode opens up a new way for the traditional cost management with its unique perspective. In this article, on the basis of discussing the theory and connotation of product life cycle cost management, we put forward that we should pay more attention to the product life cycle cost management strategies while managing the cost vertically and horizontally, and then construct the product life cycle cost management strategy framework.
\end{abstract}

\section{An Overview of Product Life Cycle}

\subsection{The Theory of Product Life Cycle}

Product life cycle refers to the whole process including self-inoculation, generation and extinction of the product ${ }^{[1]}$. The theory of product life cycle was firstly put forward by Harvard University professor Raymond Vernon in 1966 in the "the International Investment and International Trade in the Product Cycle ".Vernon hold that product life is the marketing life of a product, which is the same as people's lives experiencing the cycle of formation, growth, maturity and decline. For the product, it goes through the cycle of development, introduction, growth, maturity and decline. So the product life cycle was defined by him as the product's market life, the process of a new product from being created to enter the market to being eliminated by the market. This is the initial definition of product life cycle from the perspective of market. With the development of economy, people found that the product life cycle can also be understood from the view of the product itself. Therefore, product life cycle also refers to the whole process of product formation to demise, including product planning, development and design, production, usage and disposal[ ${ }^{[2]}$.

\subsection{The Cost Theory of Product Life Cycle}

Product life cycle cost is an important concept in the theory of product life cycle. The theory originated from a research on the cost control of military materials which conducted by the U.S. Defense Department in the early 1960s. At that time, the U.S. Defense Department required material suppliers to design and develop the provided supplies according to the certain specifications and standards and the cost of product should achieve the lowest sum in the whole life cycle, in order that they can obtain the necessary military supplies and control the expenditure of national defense. Based on the product life cycle perspective, this cost management has opened up a new idea for traditional cost management. After 1960s, with the widely used of information technology and the emergence of new economic environment, such as the diversification of social demand, reduction of product life cycle and differentiation of market, the market emerged a large number of electronic products and other high-tech products. What a unique feature for high-tech products is the quite high use-cost and disposal cost. Therefore, when consumers purchased the products which they want, they would use the lowest costs standard to decide whether the products worthy to buy or not. In order to acquire an advantageous position in the increasingly fierce competition market, it is necessary for enterprises to consider the follow-up costs and disposal costs of the product. However, the traditional cost management mode had been criticized for its gradually revealed disadvantages under the new economic situation, for example, it couldn't formulate corresponding mode of cost management according to the changes of internal and external environment in an enterprise; too much emphasis on enterprise internal production process, ignored the supply, sales and after-sales service; only paid attention to the tangible cost drivers and ignore the invisible cost drivers and so 
on $^{[3]}$. The society urgently needed a new cost management mode to manage costs. So Product life cycle cost management theory met the reality requirements and came into being.

In short, the Product Life Cycle Cost Management is the new field in which the product life cycle cost management combined with cost management theory. The theory abandons the traditional cost management narrow perspective of studying cost in production field. It provides a more macro perspective to co-ordinate the entire product life cycle cost management ${ }^{[4]}$.

\subsection{The Connotation of Product Life Cycle Cost Management}

The connotation of product life cycle cost management can't be enriched and developed without the development of social economy and the renewal of cost management strategies. Generally speaking, it can be understood from two aspects, which called "vertical" and "horizontal" management according to two different definitions of product life cycle ${ }^{[5]}$.

Vertical product life cycle cost management is to manage product costs based on market concept, which means an enterprise manages its product costs in different market periods, such as the input period (called the bud), growth period, mature period and recession period and so on ${ }^{[6]}{ }^{[7]}$. The main costs involved in each period are roughly shown in Fig. 1 below.

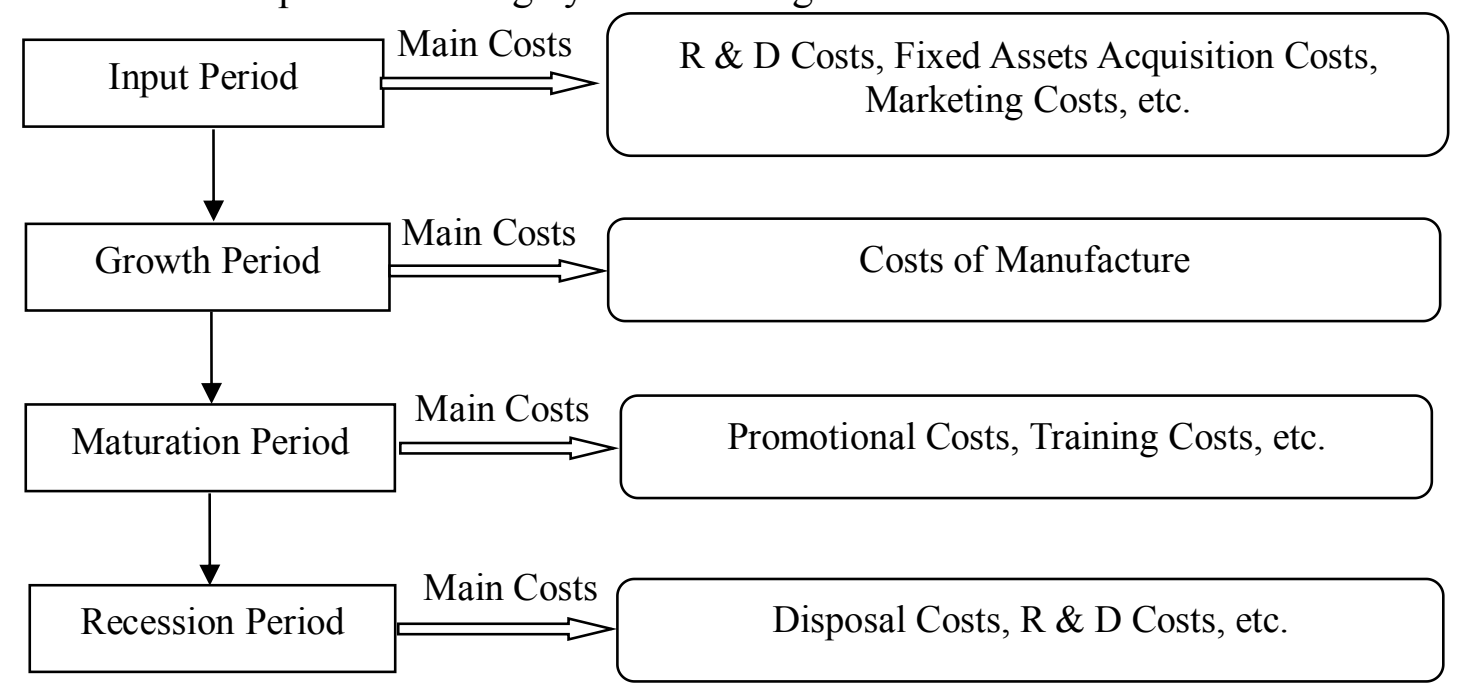

Fig. 1 The cost of vertical product life cycle

While horizontal product life cycle cost management is to manage product life cycle costs based on production concept, which means an enterprise manages its product costs in different stages, covering the whole process of researching and developing, designing, producing, sale and customer service's cost management. The costs of researching, developing and designing are also called upstream costs, while the costs of producing are also called the middle costs, sales and customer service costs are called downstream costs.

Certainly, with the increasing attention and efforts to consumer use costs and social costs, Some scholars, such as H.LIU(2002), ZH.H.ZHU(2005) ${ }^{[8]}$, F.Y.LIN(2006), F.GONG(2008) ${ }^{[9]}$ have put forward that horizontal product life cycle cost management should also be covered the subsequent product operation costs and maintenance costs, disposal costs and social responsibility costs etc., which make the product life cycle cost connotation exist three different perspectives specifically referring to "producer (enterprises)", "consumer (user)" and "society".

No matter which perspectives are adopted to manage, the above division method has its defects. As the term suggests, product life cycle cost management means the enterprise or organization manages the full life cycle costs of the product. So it's obvious that the subject of management is the enterprise or organization itself. Although the division based on the consumer (user) perspective and social perspective can expand the extension of product life cycle cost, they will relatively weaken people's attention to subject who implements the cost management at the same time. Therefore, we should highlight the role of enterprises or organizations and weaken the classification of product life cycle costs from different perspectives in the process of cost management. On the basis of the above analysis, this paper puts forward a new division of product life cycle cost which is based on the perspective of enterprises" social person". (As shown in fig.2) 


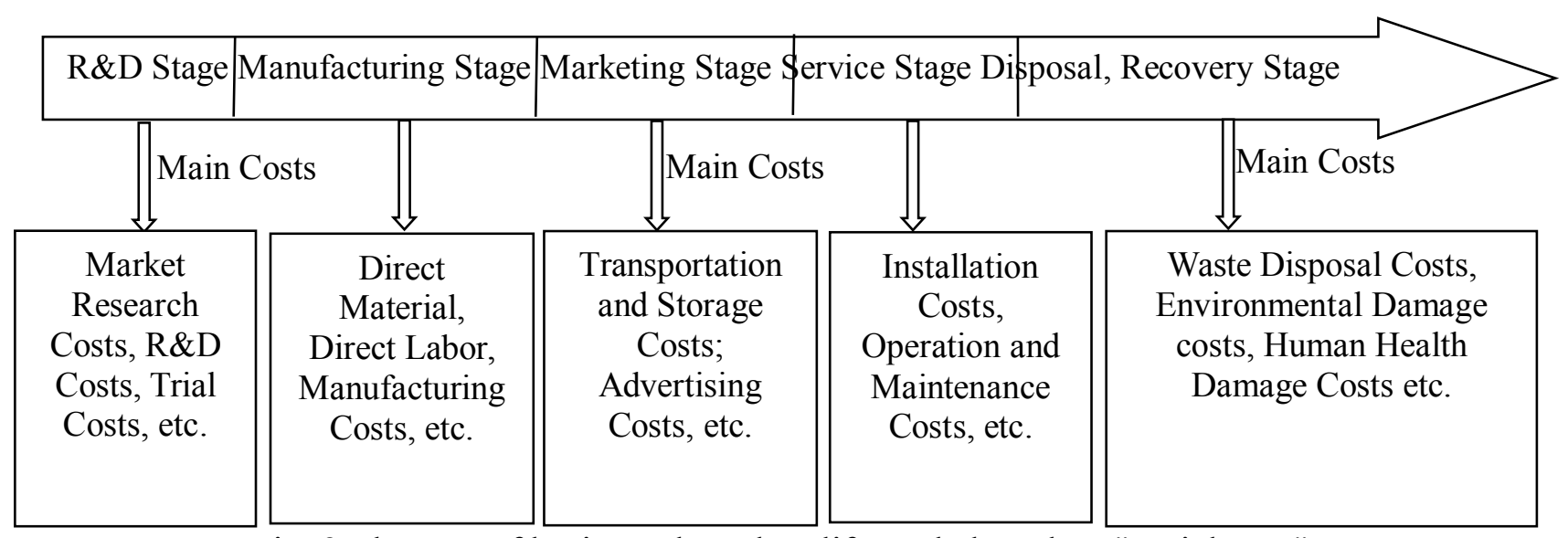

Fig. 2 The cost of horizontal product life cycle based on "social man"

\section{The Strategies of Product Life Cycle Cost Management}

\subsection{The Overall Strategy: Integration with EVM (Enterprise Value Management)}

The fundamental driving force of any enterprise' management behavior lies in the creation of the enterprise value. In each product life cycle cost management aspect and stage, its ultimate goal also pursuit the enterprise value-added. So the product life cycle cost should firstly integrate with enterprise value management. In the rapidly changing and competitive environment, the relationships between manufacturers and suppliers, distributors, retailers and customers are becoming more and more closely. An enterprise must try to understand the entire value chain if it desires to create and maintain its competitive advantage. However, enterprise value chain runs through the creation of enterprise internal value and the transfer of enterprise external value. Regardless of the enterprise's external value chain and internal value chain, value chain management can't open around the problem of cost management. Delightfully, the cost of each link in the value chain corresponds to the product life cycle cost in its form, so it provides a realistic condition for the integration. In short, the integration of product life cycle cost management and value management in order to realize the maximization of products value and finally realize the maximization of enterprise value.

\subsection{Specific Strategies}

The definition of overall strategy for us to answer the product life cycle cost management' objectives, that is, "what effects management wants to achieve ". Under the guidance of the overall strategy, we also need to refine the specific strategies to further answer the question of how to effectively implement the product life cycle cost management, that is, "what process management needs to go through ". The application of specific strategies can be reflected in the following four aspects.

\subsubsection{Integration with TCM (Target Cost Management)}

Target cost management refers to a series of management work by decomposing the target cost, implementing the cost plan, cost control, cost analysis and assessment on the basis of the cost projections, cost decision and determination target cost. Its general steps include: (1)developing a reasonable and feasible target cost; (2)depositing and implementing target cost responsibility; (3)strengthening the cost management process control; (4)establishing an effective target cost incentive system, etc. Its main spirit is focusing on the product cost management of upstream planning and design stage instead of manufacturing stage; emphasizing on product cost reduction activities beginning with the origin stage. Then it contains the whole process of the implementation of the target cost management from the stage of product design activities to the manufacturing stage, such as cost improvement, cost maintenance activities and so on. Obviously, the process of target cost management includes the cost management of product life cycle. Target cost management can provide a reasonable target cost for each stage of the product cycle. 


\subsubsection{Integration with ABCM (Activity-Based Cost Management)}

Activity management is a management method based on activity information (not only activity cost information)that helps enterprises to make positive strategic and operational decision; control enterprises production and business operation process, evaluate production and business operation performance especially the content of value-added. Operation cost calculation and operation management process are two links of AM. Based on activity, the operation cost calculation is aimed at providing accurate products and customers cost information for the enterprise. While operation management process is aimed at improving the efficiency of operation management by means of taking some effective measures and eliminating those not produce customer value operation based on analyzing activity, activity cost driver, operation performance and evaluating operation improvement to determine whether to execute assignments and evaluate the effects of implementation.

Product life cycle cost management based on activity management can make activity deep into each stage of the product life cycle, seek real costs motivation of product designing, production, marketing, and disposal, then, the product costs can be collected according to real cost motivation. Therefore, the integration between cost management and activity based cost management can strengthen the control of product cycle cost, meanwhile eliminate non value added work, finally ensure target costs can implement effectively.

\subsubsection{Integration with responsibility accounting management system}

With the rapid development of science and technology and the increasingly fierce market competition, the economic scale of enterprises has been expanding and the organizational structure is becoming more and more complex. Unified centralized management and accounting model have been unable to meet the rapidly changing internal and external requirements, and gradually be replaced by the decentralized management model. In the decentralized management mode, the enterprise management authorities must be timely effectively monitor all levels of power centers (namely responsibility center) to ensure the realization of the overall objectives of the enterprise. Therefore, in addition to pay attention to the integration of activity management, enterprises should pay attention to the integration of responsibility accounting management system in the process of implementing product life cycle cost management

The core of responsibility accounting management system lies in the setting of enterprise responsibility center. Responsibility center refers to the organization and management level of the enterprise, which has certain rights and bears the corresponding responsibilities. Further, responsibility center will be divided into cost center, profit center and investment center according to whether the enterprise cost, profit or investment occurs and can be distinguished or not. Cost center, such as factory, workshop, team etc. its responsible person generally only controlling responsibility cost, usually have no income, also need not responsible for revenue, profit or investment. Profit center is generally a higher level of responsibility center. Its responsible person can not only control costs but also control the income, thereby controlling profit. Investment center is the highest level of responsibility center that responsible for the cost, revenue, and profit and funding.

From the above classification of responsibility center, cost and profit center involves the control of related cost management. Product life cycle cost management based on responsibility accounting and management can help enterprises to define the ownership of responsibility, rights and benefits ensure the target cost implementing effectively in the product life cycle cost management process.

\subsubsection{Integration with TQCM (Total Quality Cost Management)}

Because of the product quality runs through the whole process of product design, manufacture and use, the cost management of product quality should manage the whole process of product life cycle cost. Strengthen the quality cost (prevention cost, inspection cost, external and internal loss cost) control is an important guarantee to reduce product cost, improve the market competitiveness of the enterprise products. As far as modern enterprises are concerned, we should pay attention to the following aspects of quality cost control:1 prevention costs, the cost of preventing the 
occurrence of inferior products or services in the process of providing products or services, include quality planning costs, process control costs, customer survey fee, training quality and improving working ability of costs, product evaluation fee and quality system research and management fees, fee of supplier evaluation, process plan fees, quality improvement measure cost etc. In the R \& D Stage, the cost is essential because of the quality control determines the difference of the quality of enterprise products. (2)Identification costs, which incur in order to determine whether the product or service meets customer's requirements or not, generally include the outsourcing of raw materials inspection fees, laboratory or measurement service fee, process inspection fee, examination fee, check fees and test device of adjustment cost, test materials and small equipment quality cost, product inspection fee, quality audit cost and so on. Identification costs run through the various cycles of product life. (3) Internal loss cost refers to the cost of product or service not meets the specification or customer's needs before they reach to the customer. In the product life cycle; the enterprise should as far as possible to reduce the loss in order to control product quality at an optimum level. (4)Internal loss cost, referring to the cost of product failure or defect after delivery to the customer, include product warranty cost, compensation cost, loss of returned goods, product discount loss and so on. The cost can concentrate express the level of product quality. Therefore, the product life cycle cost management under total quality management is designed to allow enterprises to minimize costs while ensuring product quality.

\section{Conclusion}

In the era of knowledge economy and information, the full life cycle cost management mode opens up a new way for the traditional cost management with its unique perspective. In addition to implementing the "vertical" and "horizontal" management, Product life cycle cost management should pay attention to the application of the relevant strategies. Because the effective application of the strategies can maximize the effect of cost management, generally speaking, the strategies can be divided into overall strategy and the concrete strategy. Firstly, the goal of product life cycle cost management is to create the enterprise value, thus its overall strategy is to combined the cost management of product life cycle with the enterprise value management. Secondly, another key of product life cycle cost management is to ensure the realization of enterprise added-value, it requires to pay attention to the specific strategy in the implementation process. Among them, specific strategies include four aspects, the integration of product life cycle and the target cost management, the integration of product life cycle and activity based cost management, the integration of product life cycle and responsibility accounting management control systems, the integration of product life cycle and total quality cost management. Under the effect of product life cycle, target cost management aims at providing reasonable cost targets for cost establishment in each stage. While activity based cost management and responsibility accounting management control system mainly aim at from reducing the cost of non-value added work and clarifying rights, responsibility and benefit to ensure the effective implementation of the target cost. The product life cycle cost management needs to focus on the quality problems of products, which reflect the requirements of the external environment for the performance of their products. It proves that cost management needs to be on the premise of quality management. Based on the above analysis, the strategy framework of product life cycle cost management can be constructed (As shown in Fig.3). 


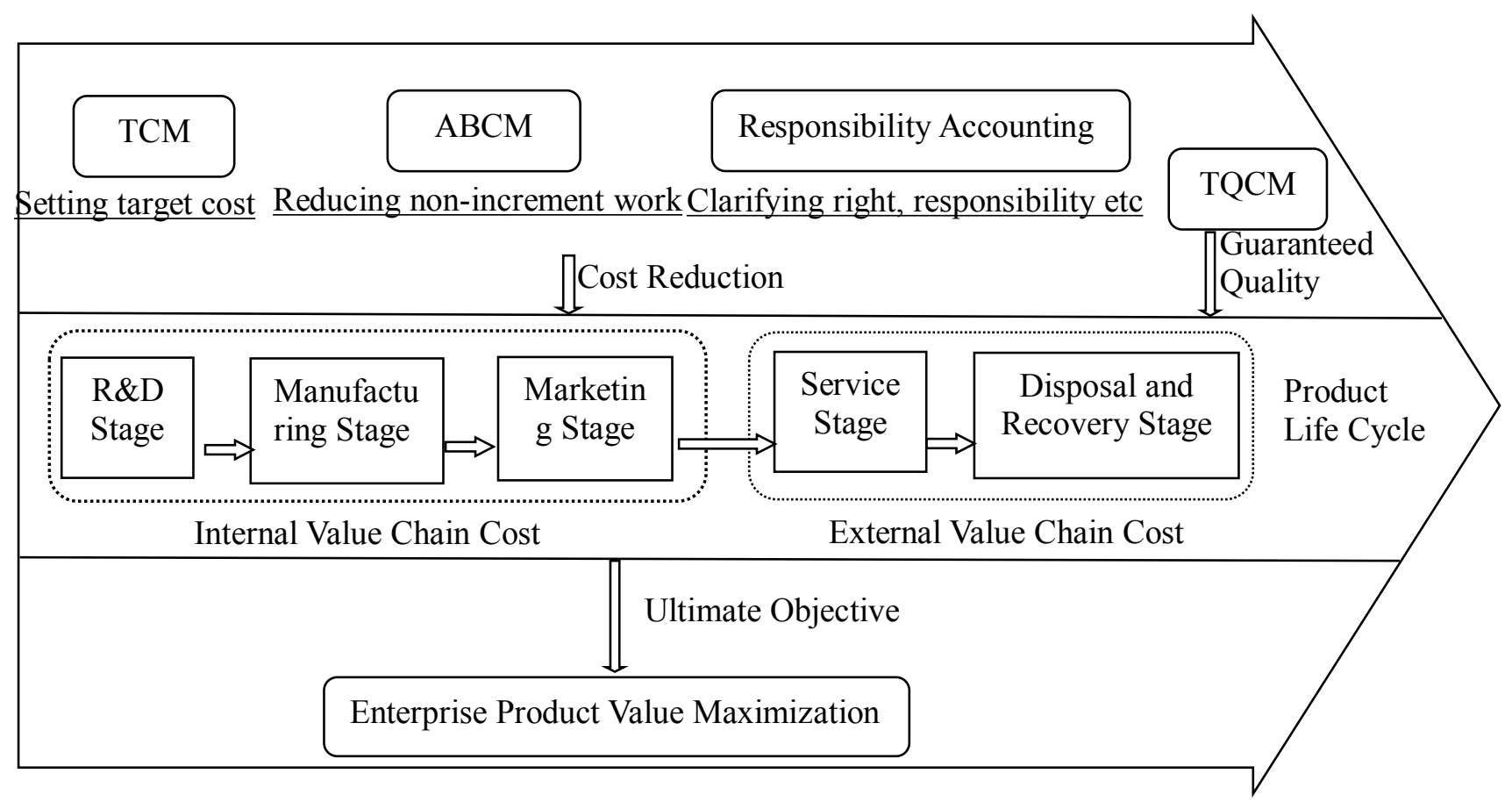

Fig. 3 The strategy framework of enterprise product life cycle cost management

\section{References}

[1]. F.LIN. "Product life cycle cost: connotation, evolution and enlightenment", Theory Journal,2006,07:69-70.(in Chinese)

[2]. F.LUO. "Research on product life cycle cost management based on value chain", Guizhou College of Finance and Economics,2011.(in Chinese)

[3]. H.LIU. "Product life cycle cost management idea and strategy", Journal of Central University of Finance and Economics, 2002,01:73-76.(in Chinese)

[4]. W.WANG, L WANG. "Research on product life cycle cost management [J]. Productivity Research, 2008,14:145-147.(in Chinese)

[5]. L.H.YU, Y.D. GONG "Two different from the perspective of product life cycle cost management". Communication of Finance and Accounting, 2010, 23:124-125.(in Chinese)

[6]. M.WANG, W.T. QUAN. "Cost management strategy based on product life cycle" [J]. Journal of Dalian Maritime University (Social Science Edition ), 2010,03:33-36.(in Chinese)

[7]. L.ZOU, "Discussion on enterprise cost management based on product life cycle", Accounting Research.2010,18:64-66.(in Chinese)

[8]. ZH.H.ZHU. "Evolution of product life cycle costs and its implications for cost management", Business Economics and Management, 2005,07:76-79.(in Chinese)

[9]. F. GONG "Research on strategic cost management based on the product life cycle", Hunan University, 2008.(in Chinese) 